\title{
Knowledge Management Research \& Practice: Visions and Directions
}

\author{
John S. Edwards, Aston University, UK \\ Sven Carlsson, Jönköping University, Sweden \\ Meliha Handzic, University of New South Wales, Australia \\ Mark Nissen, US Naval Postgraduate School, USA
}

\begin{abstract}
This editorial paper outlines key directions for knowledge management research and practice. The editorial team presents the results from a small survey of academics and practitioners about the present and future of knowledge management, and the editors include their own informed views on how this journal can help promote scholarly inquiry in the field.
\end{abstract}

\section{Introduction}

Knowledge is critical in today's global economy. Knowledge work continues to increase as a fraction of world business, and many scholars view knowledge as one of the few sustainable sources of competitive advantage. Of course people have been studying knowledge for millennia, and disciplines such as epistemology address the study of knowledge directly, but the field of knowledge management (KM) represents a relatively recent addition to the scope of academic research and enterprise practice. Unfortunately, relatively few KM articles are based on rigorous research, and most $\mathrm{KM}$ practice is not well informed by theory. This situation makes it difficult for science to progress by developing cumulative knowledge in this field, and it relegates practice to reliance upon imitation, vendor technology "solutions" and trial and error. This journal, Knowledge Management Research \& Practice (KMRP), is established to address this problematic situation as it affects both research and practice.

For the first issue of this new journal, it is appropriate to consider the state of the art in knowledge management and what expectations are held about the future. We also feel it is appropriate to provide our own informed views of the KM field, to help with direction setting and signal the academic and practitioner alike as to the kinds of topics and methods we feel are particularly important. In order to achieve this, the $K M R P$ editorial team has drawn from its own KM scholarship to outline a set of key issues and ideas, and it decided to carry out a small survey of other academics and practitioners interested in KM to better inform these speculations. This article reflects the synthesis of the two processes, and it is organized into four parts beginning with this introduction. Part 2 includes the survey method and results, and part 3 includes a set of KM visions and directions from the editorial team. The article closes with a call for action in the KM field.

\section{Survey Design}

It is appropriate to include a "health warning" here. The survey on which we report below does not reflect the kind of scale, detail and rigour that we would normally expect for a $K M R P$ article. For example, there are too few responses, there is a bias towards those who actively participate in certain KM activities, and the instrument 
used has not been validated. Thus we do not present our survey design or results as an exemplar of rigour. Rather, we were interested in quickly "feeling the pulse" of academics and practitioners for this inaugural journal issue, especially to help indicate the breadth of backgrounds and issues relevant to $\mathrm{KM}$ as it is at present. Therefore we conducted a relatively informal survey of researchers and professionals with an interest in KM.

The criterion for "interest in KM" was participation in KM conferences and e-mail lists (two of each). After pilot testing, 158 questionnaires were distributed to different people or e-mail addresses, although it is possible that in a few cases two distinct email addresses may have represented the same person. One reminder was also sent by e-mail. 25 usable questionnaires were returned, representing a response rate of $15.8 \%$. Whilst acceptable by normal survey standards, this was slightly disappointing to the authors, given the focused nature of the community. However, the length of the questionnaire, at 4 substantive pages, perhaps contributed to this.

\section{Survey Results}

The results of the analysis of the collected survey data are presented in six sections. The first examines the respondents' demographic information. The second presents respondents' views about KM, influential ideas in KM and influential people in KM. The next three sections examine their views on the most useful forms of support for KM activities; the most important types of KM technologies; and the most important factors in KM initiatives respectively. The final results section presents respondents' views on the most important challenges facing research and practice in the field of knowledge management.

\section{Respondent Demographics}

The profile of the sample is examined here in terms of the respondents' occupation, experience with $\mathrm{KM}$, subject area of academic qualifications, importance of $\mathrm{KM}$ to them as an area of work/interest, and responsibility for KM. The average respondent to this survey can be described as being an academic, with either business or technology related academic qualifications, with less than 5 years of experience in $\mathrm{KM}$, with their main interest being KM, but not necessarily having a clear position of responsibility for KM (as nearly as possible, there is an even split between those who have, and those who have not). Given the way in which the questionnaire was distributed, it seems reasonable to expect some non-response bias in that those who were less interested in $\mathrm{KM}$, and specifically in a new journal about $\mathrm{KM}$, might be expected to be less likely to respond.

\section{Occupation}

Of the total of 25 survey respondents, $68 \%$ were academics, $24 \%$ were practitioners and $8 \%$ were both (academics and practitioners), as shown in Figure 1. This distribution shows that the views of academics are somewhat over represented, and those of practitioners are somewhat under represented. This further suggests that the survey responses generated may reflect more closely the views of academics. This is, however, consistent with academics being more interested in influencing a new journal, especially one that emphasizes rigour, as $K M R P$ does. 


\section{INSERT FIGURE 1 ABOUT HERE}

\section{Experience with $\mathrm{KM}$}

The survey respondents' years of experience with KM are illustrated in Table 1 . These results show a high proportion of respondents in the 3 to 4 year experience group (56\%) and fewer respondents in the 2 and under, and 5 and over groups. In particular, $16 \%$ of the individuals from the respondent population had 1 to 2 years of experience with KM, 16\% had between 5 and 10 years of experience, while the remaining $12 \%$ had over 10 years of experience with KM. While these responses suggest that $\mathrm{KM}$ is not a recent phenomenon, they also show that it has gained an increased popularity within the last couple of years.

\section{INSERT TABLE 1 ABOUT HERE}

\section{Subject Area of Academic Qualifications}

Of the 25 individuals surveyed, the majority had their most recent subject area in business (32\%), followed by engineering (20\%) and information systems (16\%). Other subject areas represented include: social research (4\%), psychology (4\%), biology (4\%), education (4), economics (8\%), computer science $(4 \%)$ and a mix of business and computer science (4\%), as shown in Figure 2. A high proportion of respondents from business and technology areas suggests that these disciplines place particularly high value on knowledge management. The variety of disciplines mentioned confirms the multi-disciplinary nature of $\mathrm{KM}$, which KMRP is particularly concerned to strengthen.

\section{INSERT FIGURE 2 ABOUT HERE}

\section{Importance of $K M$}

All survey respondents indicated presently active interest or work in the area of KM. This is not surprising given the population sampled, but clearly indicates the relevance of the responses to the market at which KMRP is aimed. About two thirds $(68 \%)$ considered KM as their main area of interest or work, while the remaining one third (32\%) had a significant interest in KM (see Figure 3).

\section{INSERT FIGURE 3 ABOUT HERE}

\section{Special Responsibility for KM}

The distribution of responses shown in Table 2 indicates that the respondents were quite evenly divided between those who had a special responsibility for KM (52\%), and those who did not (48\%). This, together with the importance of KM to respondents reported above, suggests that all knowledge workers, KM specialists as well as non-specialists, are equally important stakeholders in KM.

\section{INSERT TABLE 2 ABOUT HERE}




\section{KM Foundations}

This section examines the respondents' opinions about the KM phenomenon, as well as their assessments of the most influential ideas and people in KM.

\section{Opinions about KM}

Table 3 shows the distribution of respondents' opinions about KM separated into those that agree (somewhat or strongly) and those that disagree (somewhat or strongly) with a series of ten statements. Thus, it was possible to identify more clearly positive and negative attitudes towards KM aspects. Each statement was rated separately by the respondents on a 5-point Likert scale where $1=$ Strongly agree and $5=$ Strongly disagree.

When asked about their opinion about knowledge, $100 \%$ of the respondents agreed that "There is some knowledge that cannot be put into explicit form". This implies a widespread recognition of the stickiness of tacit knowledge. 58\% of the respondents believed that "knowledge only exists in the minds of humans", but also that "an organisation has knowledge that goes beyond that of the people in it" $(58 \%)$, suggesting a view that knowledge combined can be greater than the sum of the parts.

There was a shared view by $71 \%$ of the respondents that "KM practice needs to be based on sound theory", and that "KM should be built around an organisation's processes, not its structure" $(65 \%)$. Furthermore, $62 \%$ of the respondents considered that "Most organisations see KM as a technological issue", and disagreed with the view that "collaboration approaches do not give enough help in implementation" $(29 \%)$.

Finally, 58\% of the respondents recognised that "There is a split between Western and Eastern approaches to KM", but only 45\% felt that "The divide between Western and Eastern approaches to KM needs to be bridged". Not surprisingly, there is a significant correlation between responses to these two statements $(0.471, p=0.027$, two-tailed). This implies a fair degree of tolerance for differences. This view is further reinforced by $83 \%$ of the respondents who strongly opposed the idea that "An organisation cannot use both collaboration (network) and codification KM strategies together".

\section{INSERT TABLE 3 ABOUT HERE}

$62 \%$ agreement with the view of $\mathrm{KM}$ as a technological issue is contrary to some earlier survey results. The most recent Australian survey, for example, found that only $6 \%$ of the respondents defined $\mathrm{KM}$ as a technological concept, and $85 \%$ as a business focused approach (Zyngier, 2001). To eliminate any possibility of bias, the responses for this question were cross-tabulated against the subject area of the respondents, as shown in Table 4. No major differences were found in ratings between respondents from business and technology focused subject areas. However, from the wording of the question, respondents here should have been answering what they perceived others (i.e. organisations in general) to be doing. This may account for some of the disparity. 
Apart from the one correlation mentioned earlier, the only other statistically significant correlation (at $\mathrm{p}=0.05$ ) was between the responses to "There is some knowledge that cannot be put into explicit form" and "KM practice needs to be based on sound theory" $(0.479, \mathrm{p}=0.018$, two-tailed $)$. This may suggest that the limitations of attempts to make knowledge explicit is one of the areas in which further theoretical development is most needed.

\section{INSERT TABLE 4 ABOUT HERE}

\section{Influential Ideas in KM}

Respondents were asked to give a textual response about the three most important ideas in KM. From the variety of themes reflected in the responses obtained, the most frequently cited as important were an integrated content-narrative-context framework of KM, and the concept of communities of practice. The third most frequently cited idea was the explicit-tacit knowledge taxonomy.

It was a little surprising that neither Nonaka and Takeuchi's SECI spiral model nor the codification-personalisation distinction of Hansen et al received any first place rankings.

The complete list of ideas is shown in Figure 4.

\section{INSERT FIGURE 4 ABOUT HERE}

To give more structure, we have grouped the ideas mentioned by respondents grouped into eight categories, as shown in Table 5:

- Business (e.g. strategy, competitive advantage)

- Culture (including leadership and organisational learning)

- Intellectual capital

- $\quad$ Practice of KM

- $\quad \mathrm{KM}$ as process

- Social capital and networking (e.g. Communities of practice)

- Technology

- Theories about knowledge

These may therefore indicate some of the topics we might expect to be addressed in articles submitted to $K M R P$ in the near future.

\section{INSERT TABLE 5 ABOUT HERE}

As might be expected, theories about knowledge appeared most often and were most highly ranked. Cultural concepts, and issues related to social capital and (human) networking were close behind. Business aspects were ranked first three times.

Although seven respondents mentioned ideas specifically related to practice or the application of theories, no-one ranked these first. Again, this is perhaps unsurprising; there needs to be some sound theory before issues of practice can really be considered.

\section{Influential People in KM}


Respondents were asked to name the three most influential authors/teams of authors on KM. The distribution of responses shown in Figure 5 clearly identifies Nonaka as the most influential single author in KM, followed by Nonaka and Takeuchi as a team of authors. We are pleased to be able to include a paper co-authored by Nonaka in this first issue of $K M R P$. Davenport and Prusak as a team hold a strong third position (when higher ranks are weighted more). The remaining responses are divided quite evenly among more than twenty other authors.

\section{INSERT FIGURE 5 ABOUT HERE}

\section{KM Activities and Support}

Respondents were asked to fill in what they believed were the most useful forms of support for each of a set of KM-related activities, under the headings of IT/software support and non-computer support. Here we give a lesson regarding rigour. A substantial minority interpreted this set of questions as asking for a vote between the two types of support for each activity; this was not the intention, and such responses have been disregarded. Although the questionnaire had been given a small-scale pilot (five respondents), this problem did not surface - perhaps because the pilot sample was too homogeneous (all UK academics). Table 6 shows a simple count of responses given to the set of questions about useful forms of support (IT and non-IT) for activities relating to the management of knowledge. These numbers indicate that respondents consider that both IT and non-IT support are equally useful for all activities except one. For the knowledge valuation activity, non-IT forms of support were more frequently indicated as useful.

\section{INSERT TABLE 6 ABOUT HERE}

The detailed responses were more notable for their diversity than for any specific patterns. Under most of the sixteen headings, it was unusual for any type of support to be mentioned by more than one respondent. This is testament to the breadth of activities that KM needs to encompass, and which KMRP aims to cover. It is also clear that there is no "one size fits all" way to "do" knowledge management. The next two sub-sections consider IT and non-IT support in a little more detail.

\section{IT/software support}

Two elements of the responses are worthy of mention: support for knowledge retention, and the role of groupware.

Knowledge retention was the activity with the clearest consensus as to the most useful form of IT support, with 6 votes for some form of knowledge repository and 3 for some form of content management system.

Groupware (including collaboration tools) was the type of software that was mentioned by far the most often overall (13 times). Knowledge sharing produced 5 votes for groupware plus one for collaboration tools, and knowledge creation yielded 3 for groupware, plus again one for collaboration tools. Groupware was also mentioned twice under knowledge integration and once under knowledge use. Respondents clearly perceived it as the most generally useful software tool for KM. 


\section{Non-IT support}

Only four forms of support were mentioned more than once for a particular activity. Brainstorming was mentioned 5 times out of 11 under knowledge creation, face-toface interaction of some kind 3 times out of 12 for knowledge sharing, reports twice out of 11 for knowledge retention, and team working 3 times out of 10 for knowledge integration.

\section{KM Technologies}

Respondents were asked to write in "the most important types of technology that can provide support for KM" (up to three). Internet/Intranet/Extranet/Portals combined were most frequently cited, as shown in Figure 6. This is especially interesting given that these were very rarely cited as the most useful form of support for any particular $\mathrm{KM}$ activity, in answers to the previous question. When considering all other responses of high importance, groupware (as would be expected from the previous section), search/retrieval and data-mining tools were rated among the highest. Among the rest, communication and collaboration technologies were generally cited as important more frequently than knowledge retrieval and discovery technologies. These, in turn, were cited more than technologies for storage and preservation of knowledge or various other support devices.

\section{INSERT FIGURE 6 ABOUT HERE}

\section{KM Influences}

This section examines and compares the respondents' opinions about how KM relates to different aspects of an organisation's work. The respondents rated different factors in terms of the importance placed on these factors in KM initiatives.

\section{Given Importance}

With respect to the importance that is usually placed on different aspects of an organisation's work in KM initiatives, the responses shown in Table 7 and in Figure 7 inform us that technology is the single most important aspect. Technology was most cited as an important factor by the respondents (79\%), followed by business tasks and processes $(63 \%)$. In contrast, culture was indicated as being rarely considered in KM initiatives. Only $33 \%$ of the responses rated this factor as important. Similarly, less than $50 \%$ of responses rated as important factors: people (46\%), structure (43\%) and performance/measuring outcomes (38\%). Overall, these responses reveal a dominant role played by technology in an organisation's KM initiatives.

However, we need to include a word of warning here, again related to rigour. A high rating of "how much importance is usually placed on technology in a KM initiative in an organisation" here and agreement with "most organisations see KM as a technological issue" earlier appear to be addressing the same construct. Yet there was no correlation at all $(\mathrm{r}=-0.093, \mathrm{p}=0.664)$ between the two sets of responses! This raises some questions about the validity of our questionnaire instrument. INSERT TABLE 7 ABOUT HERE

\section{INSERT FIGURE 7 ABOUT HERE}




\section{Desired Importance}

With respect to the importance that should be placed on different aspects of an organisation's work in KM initiatives, shown in Figure 8 and Table 8, most responses rate people, culture, tasks \& processes, and performance/measuring outcomes as quite important. People and culture were most cited as important factors (96\% and $92 \%$ respectively). Tasks and processes were also acknowledged as important (84\%), as were performance / measuring outcomes (79\%). Scores obtained for technology $(41 \%)$ and structure $(50 \%)$ indicate that the respondents believed that there should be less importance placed on these aspects. Overall, these responses reveal a desire to place a greater emphasis on human aspects of an organisation's work in an organisation's KM initiatives.

\section{INSERT TABLE 8 ABOUT HERE}

\section{INSERT FIGURE 8 ABOUT HERE}

\section{Given vs. Desired Importance}

A comparison of the respondents' opinions about actual and desired importance placed on different factors in KM initiatives is shown in Figure 9. A series of paired T-tests was performed to compare the average actual and desired importance scores for different factors. The results, shown in Table 9, indicate that the respondents tended to think that there was significantly greater than desired importance given to technology, and significantly less than desired emphasis placed on people, culture, tasks \& processes, and performance/measuring aspects in an organisation's KM initiatives. No significant difference was found between actual and desired importance scores for structure.

\section{INSERT FIGURE 9 ABOUT HERE}

\section{INSERT TABLE 9 ABOUT HERE}

Interestingly, the overall average scores also rose significantly, from 3.36 for the given importance to 4.01 for the desired importance. This suggests a widespread belief that organisations need to consider KM initiatives more carefully, taking into account a broader range of factors.

\section{Challenges for Research and Practice}

The following section examines major challenges for knowledge management research and practice.

\section{Challenges for Research}

Respondents were first asked to give a textual response about the most important challenge facing research over the next three years. There were a variety of themes in responses obtained as demonstrated in Table 10. The challenge mentioned most often (20\%) was the need for a consistent and cohesive theory supported by empirical evidence to provide sound and stable foundations for the field. This is one of the main 
objectives of KMRP. Some respondents $(8 \%)$ indicated that connecting research and practice was the most important challenge for them. Again, this is one of KMRP's main objectives. Others felt that finding and measuring business benefits was the key issue. Other notable general issues mentioned by the respondents include tacit knowledge, context, and integration of disparate KM elements.

\section{INSERT TABLE 10 ABOUT HERE}

\section{Challenges for Practice}

Respondents were also asked to give a textual response about the most important challenge facing practice over the next three years. As shown in Table 11, there were a large variety of responses. The challenge mentioned most often (16\%) was evaluation and measurement. Among other more often mentioned challenges were: choosing right KM strategy ( $8 \%$ ), creating trust-based organisational culture (8\%), and demonstrating value of and motivating people to share knowledge $(8 \%)$. There were a variety of elements reflected in the remaining $60 \%$ responses including demystification, gaining acceptance, regaining credibility, and making KM a part of practice and daily processes of an organisation.

\section{INSERT TABLE 11 ABOUT HERE}

\section{Editorial Visions}

The editorial team for this journal is committed to promoting rigorous and practical research on KM. In this section we summarize the vision for KM from the perspective of the team, and we synthesize this vision into a direction setting statement about the journal. For ease of presentation, we first organize the four individual visions of each editorial team member, then we include the synthesized vision from the perspective of the journal.

\section{Vision 1 - John Edwards, Editor}

My vision is for Knowledge Management Research \& Practice to become the journal to which authors of high-quality papers on knowledge management would choose to submit their work. Let us consider this in more detail.

At present, the knowledge management literature appears somewhat fragmented. There are some journals specializing in knowledge management, but many of the most influential articles on knowledge management appear in journals devoted to the researchers" "home" discipline. Our small survey yielded a range of disciplines including business, engineering, information systems, economics, social research and even evolutionary biology. Organisational sociology or human resources would be just as likely, as would many others.

This has two effects. One is that rather than a single body of literature on knowledge management, there are several knowledge management literatures. The second is that multi-disciplinary research tends to be discouraged, because of the difficulty of finding a suitable outlet for publication. Consequently, aspects of the literature which should be taking the form of debates, appear instead as unbridgeable splits. These 
splits include those between people who favour a codification strategy on knowledge management and those who favour a personalisation strategy, and between "Western" (meaning North American) and "Eastern" (meaning Japanese) approaches.

My vision is that Knowledge Management Research \& Practice can not only accommodate different perspectives, but also seek common ground between them, and integrate diverse concepts in a complementary fashion. The articles may be empirical research papers, theoretical papers, conceptual papers, case studies or surveys. Their authors may be academics, practitioners or a joint team. Their common element will be rigour and openness to ideas springing from different paradigms.

\section{Vision 2 - Sven Carlsson, Regional Editor - Europe, Middle East and Africa}

To a large extent I share my colleagues' visions for Knowledge Management Research \& Practice, but here I outline four complementary views.

First, much of the KM research has an intra-organisational perspective. Some studies indicate that the most valuable knowledge source for competitive advantage lies in organisations' networks of external relationships. Research addressing KM in the extended organisation will be valuable to the KM-field. Studies focusing on KM in the extended organisation have so far primarily studied R\&D and new product development processes, but studies focusing on KM in other types of processes are needed, for example KM around traditional processes such as the order management processes in supply chains.

Related to my first complementary view is the general question of level of analysis. I envision that KMRP will be a place where KM studies having micro, mezzo, and macro levels of analysis will find their home. I especially foresee interesting studies straddling different levels of analysis.

Second, an underlying assumption of KM and this journal is that a firm's competitive advantage to a large extent flows from its unique knowledge and how it manages knowledge. I think too little empirical evidence exists to show that this assumption is true. A stream of research could address the question of what is the strategic value of knowledge. Related to this is that KM research in general should produce ever more detailed answers to the question of why a KM initiative works for whom and in what circumstances. A problem to tackle in addressing this question is the divergent meaning of the concepts of knowledge and knowledge management when comparing the theoretical (conceptual) and empirical literatures. For example, how can we operationalise abstract theoretical concepts? There is also a need to understand discrepancies in empirical findings and what we can learn from them about the strategic dimension of KM.

Third, the phrase "Research \& Practice" points to the differences between "traditional" sciences and design sciences - the latter concerning the sciences of the artificial and design theories. Sciences aim at understanding reality, and focus on exploring, describing and explaining phenomena. Design sciences attempt to create things that serve human purposes. They aim to change existing situations into preferred ones. I envision that $K M R P$ will not only have research and practice contributions, but will actually be a bridge between the research and the practice. 
Fourth, regarding research approaches and theories, my view is that for advancing the KM-field we should be more open to different approaches and theories. Not only that, but I would like to see: 1) multidisciplinary research drawing on different disciplines; 2) research using multi-paradigm approaches (meta-triangulation) by employing disparate theoretical perspectives; and 3) research using multi-methodology by employing different research methods (even from different perspectives).

\section{Vision 3 - Meliha Handzic, Regional Editor - Asia-Pacific}

My vision is for Knowledge Management Research \& Practice to play a major role in addressing unresolved issues, challenges and opportunities in research and practice of knowledge management (KM).

At present, the development of a cohesive theory supported by empirical evidence appears to be the greatest challenge. Our survey respondents share this editorial view. Meeting this challenge will require both conceptual and empirical studies of the KM phenomena and integration of diverse concepts into holistic and integrated frameworks. Seeking common and unifying ideas, the articles may draw from a variety of disciplinary perspectives and explore topics ranging from KM foundations, through knowledge resources, processes and socio-technical influences, to outcomes of KM.

The other more specific challenge, in my opinion, is determining the role of information systems and technology (IS/IT) in knowledge management. Currently, opinions on the issue are quite divided. Our small survey identifies technology as an important KM concept, but also recognises a significant over-emphasis placed on technology in current KM initiatives by organisations. Resolving the issue of the "right" place of IS/IT in KM will require studies on whether and how successfully IS/IT can be integrated into processes of creation, storage, transfer and utilisation of knowledge in organisations.

Finally, it should be remembered that the principal motive for KM research is to reliably inform KM practice. Business managers are often sceptical of the immediate practical value of academic research and there is a role for Knowledge Management Research \& Practice in alleviating that scepticism. This will require producing proven techniques for managing the knowledge resources in organisations. In the research arena, this can be achieved through rigorous studies that can reliably establish what works and what does not, and under what circumstances.

\section{Vision 4 -Mark Nissen, Regional Editor - the Americas}

My vision for Knowledge Management Research \& Practice shares several scenes in common with those above (e.g., integration of "hard" and "soft" approaches, need for multidisciplinary research, criticality of rigorous research), on which I do not elaborate further here. Instead I outline four complementary views that are perhaps unique to my perspective as an information systems scholar.

First, many scholars view knowledge as distinct from information (and data), but few $\mathrm{KM}$ articles appear to reflect such distinction. Being able to appreciate and articulate 
how knowledge is unique and how its unique aspects can be managed represents a central aspect of my KM vision. If research and practice is unable to address the management of knowledge as distinct from information/data, then I see little that the study of KM has to offer over and above the past four decades of knowledge accumulated through effective research and practice of information/data management.

Second, I do not view the role of information technology (IT) as a necessary component of KM, and it is certainly not a sufficient element. Indeed, research and practice that center on IT have good potential to be misguided in my view. Alternatively, IT offers excellent potential to complement people and organizations in the KM context; hence research and practice that integrate IT, people and organizations appear likely to produce new, actionable and generalizable KM knowledge.

Third, I foresee critical interactions between research and practice through two temporal pairings. In the one pairing in which research follows practice, excellent lessons can likely be learned and generalized from failures as well as successes. In the other pairing in which research leads practice, the number of failures can likely be reduced through development of actionable theory to inform the manager and knowledge worker.

Finally, knowledge appears to be truly fundamental to work in the organizational context. As such, how knowledge is managed in an organization may turn out to be as or more important than any other management activity. Of course this remains speculation today. But my KM vision includes understanding knowledge first and centrally, with the idea of discovering how other management issues (e.g., planning, organizing, decision making) should be based on such understanding of knowledge.

\section{Combining the Visions}

Drawing these four editorial visions together, we see a constructive tension in place, between difference and integration. KMRP, and indeed knowledge management in general should embrace difference - differences in perspective, differences between disciplines, differences in levels of analysis, differences between the concerns of research and those of practice. These differences are to be embraced rather than eliminated; they serve to make the field more fruitful and relevant. But they need to be embraced in a spirit of integration, of debate, of complementarity, of building bridges; and the most important of those bridges is the one between research and practice, whether research leads practice or follows it. All of this needs to be done with the necessary rigour to convince people, whether academic or practitioner, of the usefulness of knowledge management and its study. Specific aspects where special emphasis may be needed at present include the role of information systems and IT in $\mathrm{KM}, \mathrm{KM}$ in the extended (and perhaps virtual) organisation, and what KM offers and above information management.

\section{The Future of Knowledge Management}

From the questionnaire responses, and the editorial team's visions, it is clear that knowledge management covers a very broad and somewhat fragmented field. The people who are interested in, and involved in knowledge management come from a 
wide range of educational backgrounds, and have a wide range of concerns, from the cultural to the technological, and from social capital to business strategy.

The most important single challenge - but really it binds all issues together - is to produce a coherent and cohesive body of theory, based on empirical evidence.

Perhaps the most specific issue is shown by survey respondents' concern about the emphasis that they believe is currently given to technology in KM initiatives, although they still rate technology as an important factor. There is a strong support for a view that "knowledge only exists in the minds of humans", as witness the significant partial correlation between the responses to that statement and the importance value that should be placed on people, even when controlled for the importance that is usually placed $(\mathrm{r}=-0.466$, the negative sign being because the scales run in opposite directions, $\mathrm{p}=0.022$, two-tailed).

Knowledge Management Research \& Practice will try to play its part in helping to produce and disseminate this coherent and cohesive body of theory, and by providing empirical evidence. In so doing, it will try to balance human, technological and organisational aspects of knowledge management, and include any other issues that may arise in KM, such as physical space or even fashions in knowledge.

\section{References}

HANSEN MT, NOHRIA N and TIERNEY T (1999) What's your strategy for managing knowledge? Harvard Business Review 77(2), 106-116.

NONAKA I and TAKEUCHI H (1995) The knowledge-creating company, how Japanese companies create the dynamics of innovation. Oxford University Press, New York and Oxford.

ZYNGIER S (2001) The role of technology in knowledge management: Trends in the Australian corporate environment. In Knowledge Management in Context (Burstein $\mathrm{F}$ and Linger H, eds), 78-92, Australian Scholarly Publishing, Melbourne. 


\section{List of Figures and Tables}

Figure $1 \quad$ Main occupation of respondents

Figure 2 Subject area of respondents' qualifications

Figure 3 Importance of KM as an area of respondents' interest/work

Figure 4 Respondents' views of the most important ideas in KM

Figure 5 Respondents' views of the most important authors in KM

Figure 6 Respondents' views of important types of technology to support KM

Figure 7 Respondents' views of the importance that is usually placed on

different aspects

Figure 8 Respondents' views of the importance that should be placed on different aspects

Figure 9 Comparison of perceived and desired levels of importance placed on different factors

Table 1 Respondents' experience in knowledge management

Table 2 Respondents' responsibility for KM

Table 3 Respondents' views about ten statements relating to KM

Table 4 Respondents' views on "most organisations see KM as a technological issue" broken down by subject of most recent qualification

Table 5 Categorisation of views about the most important ideas in KM

Table $6 \quad$ Preferences for different forms of support for various KM activities

Table 7 The importance that is usually placed on different aspects

Table 8 The importance that should be placed on different aspects

Table 9 Comparison of perceived and desired levels of importance placed on different factors

Table $10 \quad$ Challenges for KM research

Table $11 \quad$ Challenges for KM practice 


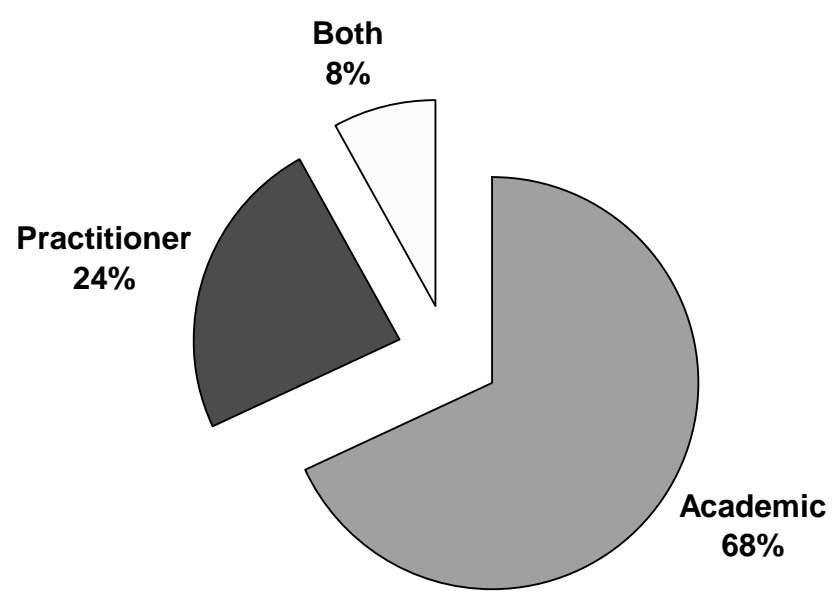

Figure 1 


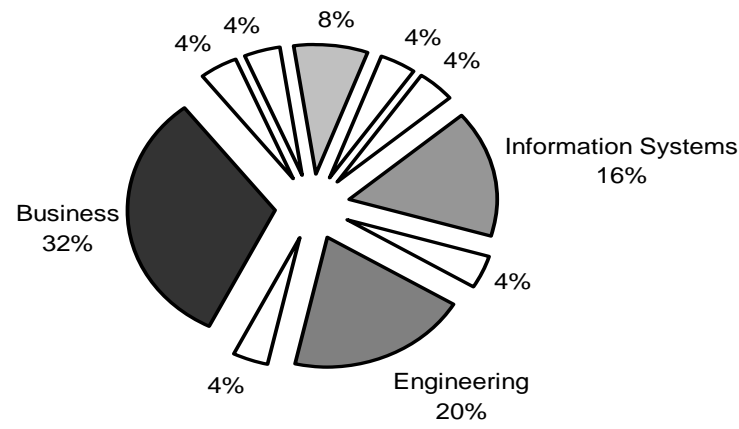

口 Social Research

口 Psychology

口Information Systems ㅁvolutionary Biology

口 Engineering

口 Adult Education

a Computer Science

口Economics

ㅁ Business \& Computer

Figure 2 


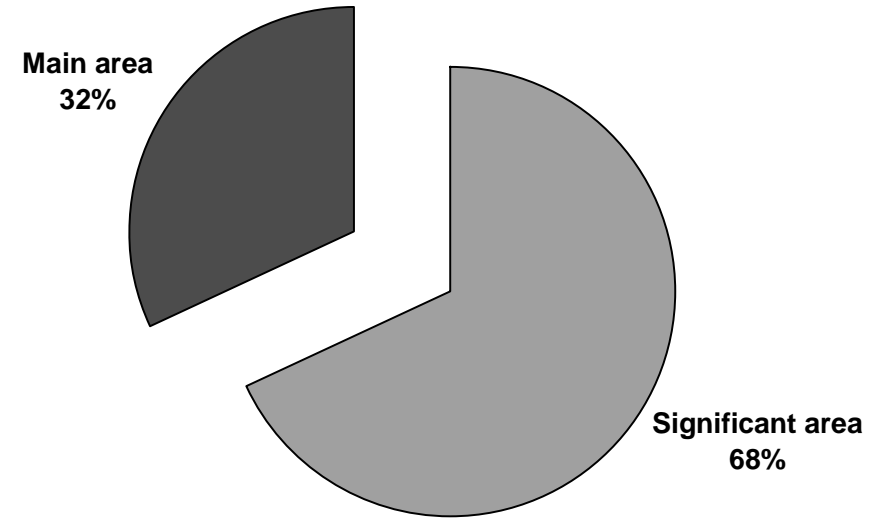

Figure 3 


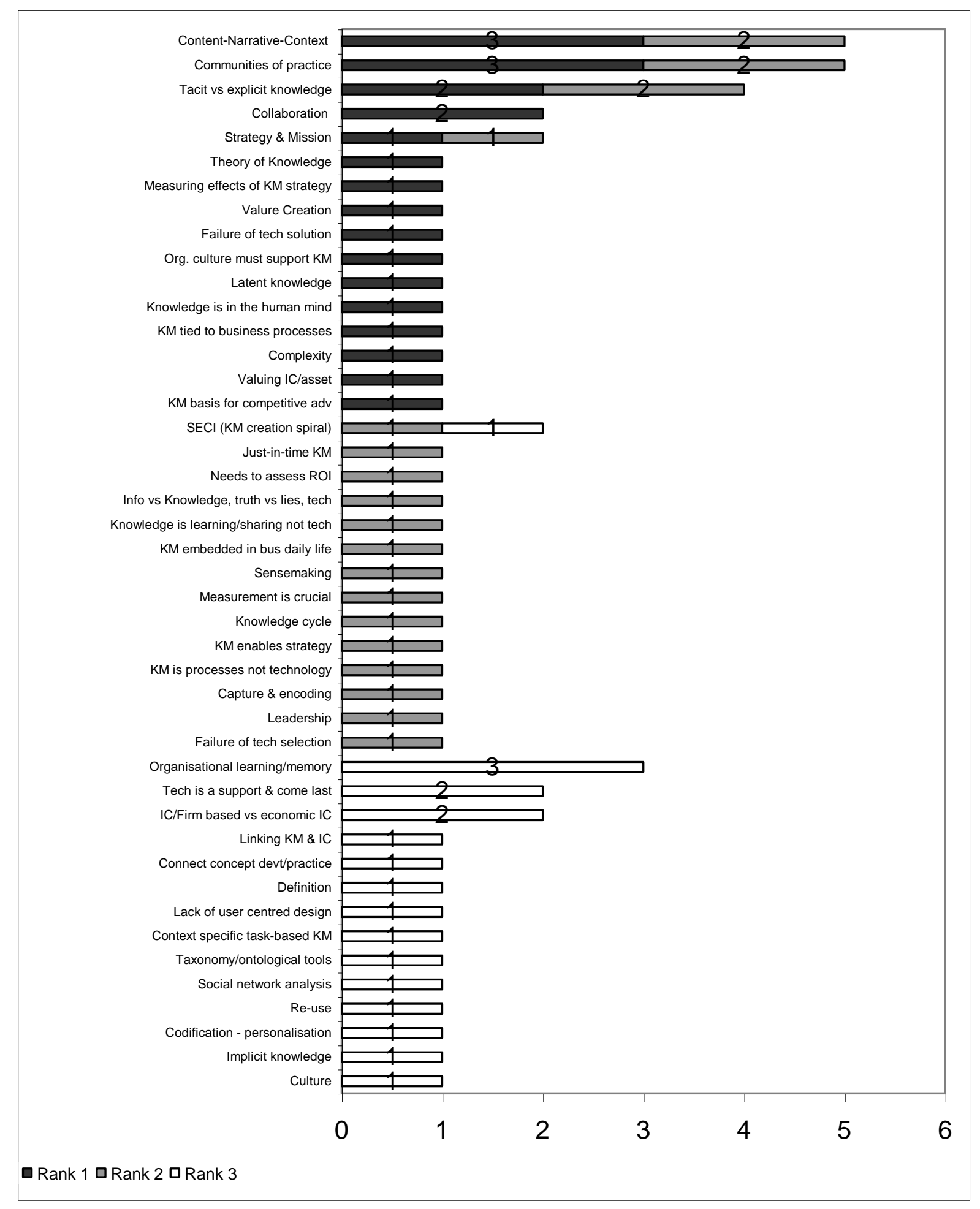

Figure 4 


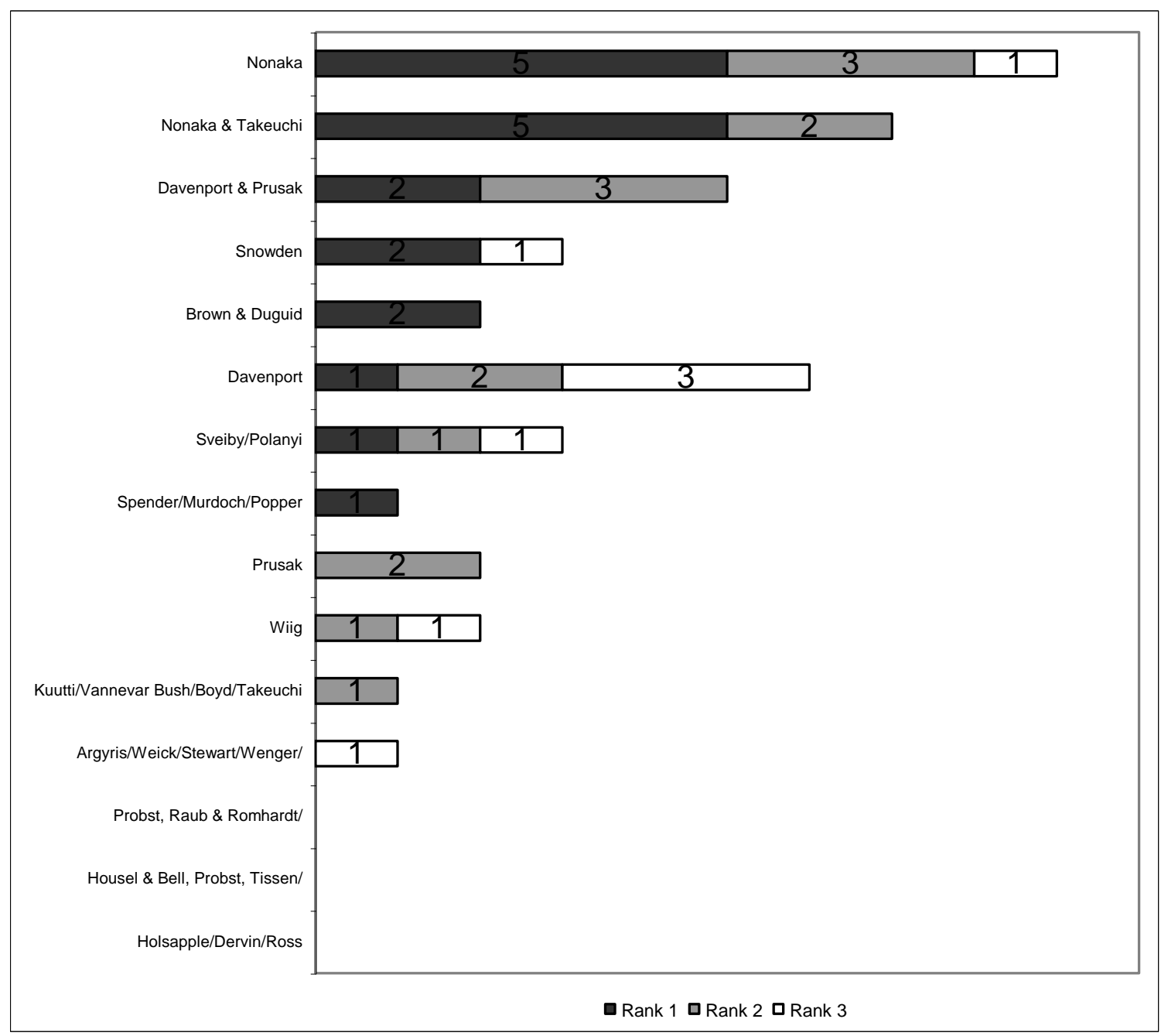

Figure 5 


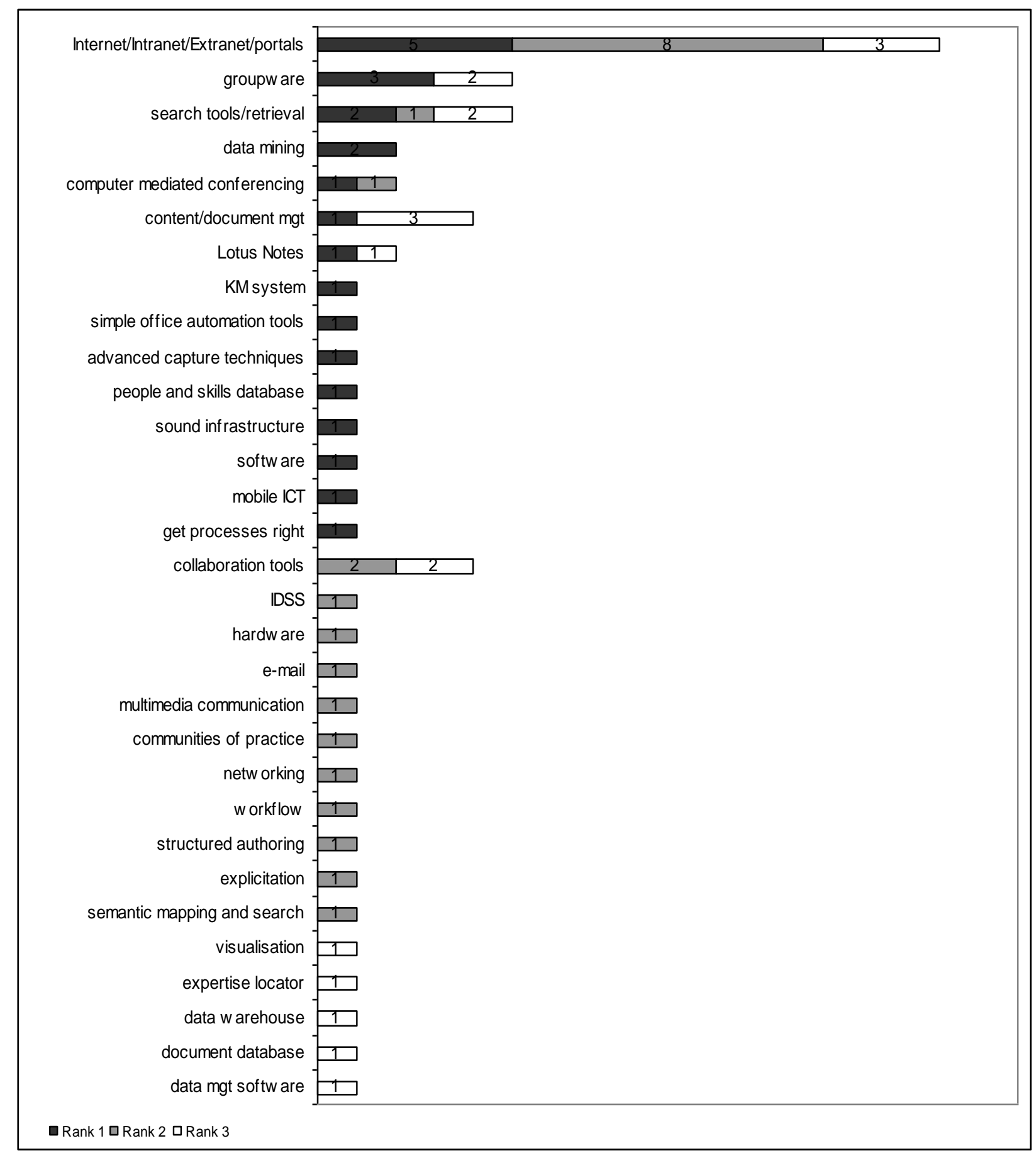

Figure 6 


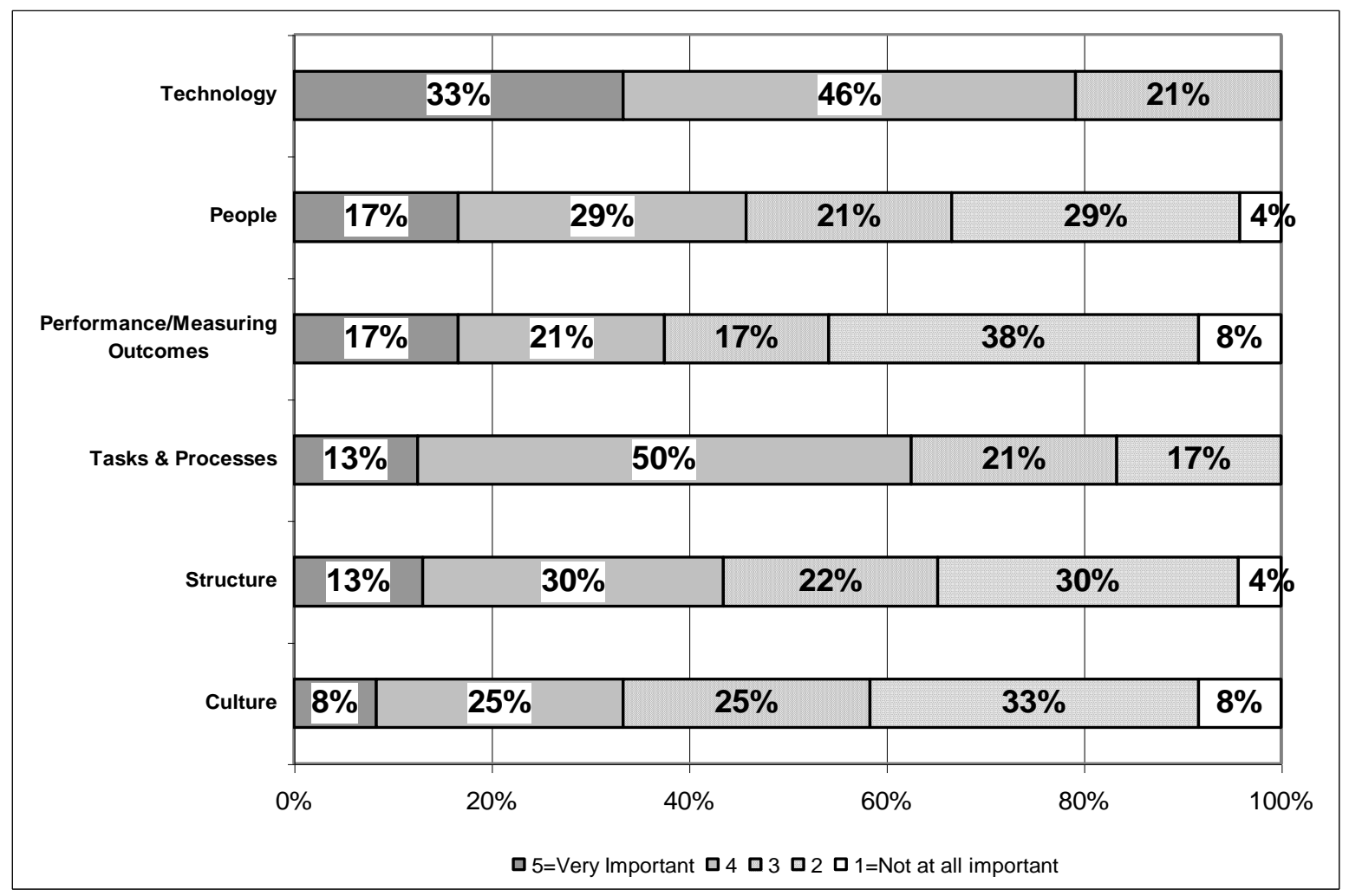

Figure 7 


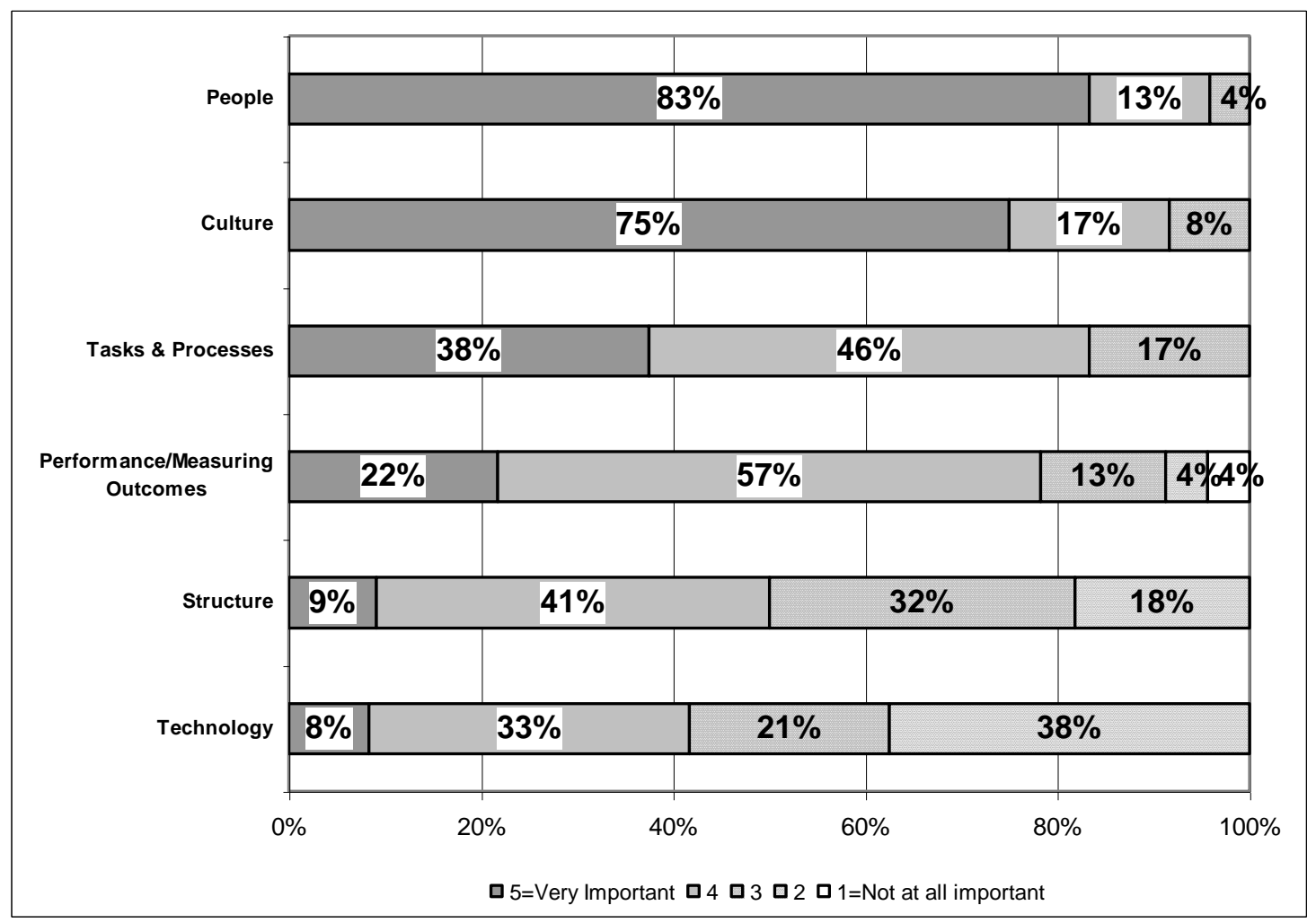

Figure 8 


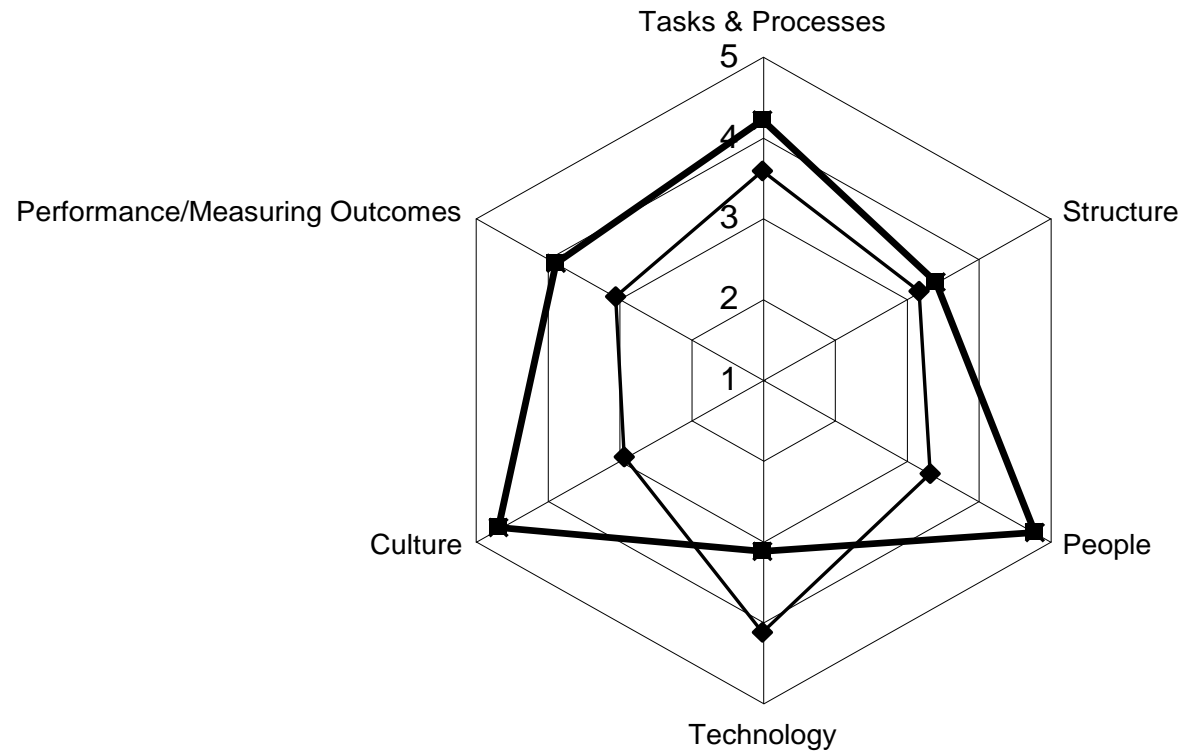

$\neg$ Given level

Figure 9 


\begin{tabular}{|ccr|}
\hline & Experience with KM \\
Year(s) & Number of Respondents & $\%$ \\
1 & 1 & $4 \%$ \\
2 & 3 & $12 \%$ \\
3 & 8 & $32 \%$ \\
4 & 6 & $24 \%$ \\
5 & 1 & $4 \%$ \\
7 & 2 & $8 \%$ \\
10 & 1 & $4 \%$ \\
18 & 2 & $8 \%$ \\
25 & 1 & $4 \%$ \\
Total & 25 & $100 \%$ \\
\hline
\end{tabular}

Table 1 


\begin{tabular}{|ccc|}
\hline \multicolumn{3}{|c|}{ Special responsibility } \\
Yes & Number of respondents & $\%$ \\
No & 13 & $52 \%$ \\
Total & 12 & $48 \%$ \\
\hline
\end{tabular}

Table 2 


\begin{tabular}{|c|c|c|}
\hline Statements & Agree & Disagree \\
\hline $\begin{array}{c}\text { The divide between Western and Eastern approaches to } \\
\text { KM needs to be bridged }\end{array}$ & $45 \%$ & $22 \%$ \\
\hline $\begin{array}{c}\text { There is a split between Western and Eastern } \\
\text { approaches to KM }\end{array}$ & $59 \%$ & $9 \%$ \\
\hline $\begin{array}{c}\text { Knowledge only exists in the minds of humans } \\
\text { the people in it }\end{array}$ & $58 \%$ & $37 \%$ \\
\hline $\begin{array}{c}\text { An organisation has knowles beyond that of } \\
\text { Most organisations see KM as a technological issue } \\
\text { KM should be built around an organisation's processes, }\end{array}$ & $58 \%$ & $25 \%$ \\
\hline $\begin{array}{c}\text { KM practice needs to be based on sound theory } \\
\text { form }\end{array}$ & $65 \%$ & $21 \%$ \\
\hline $\begin{array}{c}\text { There is some knowledge that cannot be put into explicit } \\
\text { An organisation cannot use both collaboration (network) } \\
\text { and codification KM strategies together }\end{array}$ & $100 \%$ & $9 \%$ \\
\hline $\begin{array}{c}\text { Collaboration approaches do not give enough help with } \\
\text { implementation }\end{array}$ & $12 \%$ & $8 \% \%$ \\
\hline
\end{tabular}

Table 3 


\begin{tabular}{|c|c|c|}
\hline Subject Area & Agree & Disagree \\
\hline Business + Economics & 7 & 1 \\
\hline Engineering+ IS+CS & 7 & 3 \\
\hline Other & 1 & 1 \\
\hline
\end{tabular}

Table 4 


\begin{tabular}{|l|l|l|l|l|}
\hline Category & $\begin{array}{l}\text { Number of } \\
\text { different } \\
\text { ideas }\end{array}$ & Rank 1 & Rank 2 & Rank 3 \\
\hline$-\begin{array}{l}\text { Business (e.g. strategy, } \\
\text { competitive advantage) }\end{array}$ & 5 & 3 & 3 & 0 \\
\hline $\begin{array}{l}\text { Culture (including } \\
\text { leadership and } \\
\text { organisational learning) }\end{array}$ & 6 & 4 & 4 & 4 \\
\hline$-\quad$ Intellectual capital & 4 & 2 & 0 & 3 \\
\hline$-\quad$ Practice of KM & 7 & 0 & 3 & 4 \\
\hline$-\quad$ KM as process & 1 & 1 & 1 & 0 \\
\hline$-\begin{array}{l}\text { Social capital and } \\
\text { networking (e.g. } \\
\text { Communities of } \\
\text { practice) }\end{array}$ & 4 & 5 & 3 & 1 \\
\hline$-\quad$ Technology & 6 & 1 & 3 & 3 \\
\hline$-\begin{array}{l}\text { Theories about } \\
\text { knowledge }\end{array}$ & 10 & 6 & 5 & 4 \\
\hline
\end{tabular}

Table 5 


\begin{tabular}{|c|c|c|}
\hline Activity & IT & Non-IT \\
\hline Knowledge creation & 9 & 11 \\
\hline Knowledge acquisition & 11 & 12 \\
\hline Knowledge sharing & 11 & 12 \\
\hline Knowledge retention & 12 & 11 \\
\hline Knowledge valuation & 5 & 10 \\
\hline $\begin{array}{c}\text { Knowledge } \\
\text { use/application }\end{array}$ & 8 & 10 \\
\hline Knowledge discovery & 11 & 11 \\
\hline Knowledge integration & 9 & 10 \\
\hline
\end{tabular}

Table 6 


\begin{tabular}{|c|c|c|c|c|c|}
\hline Factors & $\begin{array}{c}1=\text { Not at all } \\
\text { important }\end{array}$ & 2 & 3 & 4 & $\begin{array}{c}5=\text { Very } \\
\text { Important }\end{array}$ \\
\hline Tasks \& Processes & 0 & 4 & 5 & 12 & 3 \\
\hline Structure & 1 & 7 & 5 & 7 & 3 \\
\hline People & 1 & 7 & 5 & 7 & 4 \\
\hline Technology & 0 & 0 & 5 & 11 & 8 \\
\hline Culture & 2 & 8 & 6 & 6 & 2 \\
\hline $\begin{array}{c}\text { Performance/Measuring } \\
\text { Outcomes }\end{array}$ & 2 & 9 & 4 & 5 & 4 \\
\hline
\end{tabular}

Table 7 


\begin{tabular}{|c|c|c|c|c|c|}
\hline Factors & $\begin{array}{c}1=\text { Not at all } \\
\text { important }\end{array}$ & 2 & 3 & 4 & $\begin{array}{c}5=\text { Very } \\
\text { Important }\end{array}$ \\
\hline Tasks \& Processes & 0 & 0 & 4 & 11 & 9 \\
\hline Structure & 0 & 4 & 7 & 9 & 2 \\
\hline People & 0 & 0 & 1 & 3 & 20 \\
\hline Technology & 0 & 9 & 5 & 8 & 2 \\
\hline Culture & 0 & 0 & 2 & 4 & 18 \\
\hline $\begin{array}{c}\text { Performance/Measuring } \\
\text { Outcomes }\end{array}$ & 1 & 1 & 3 & 13 & 5 \\
\hline
\end{tabular}

Table 8 


\begin{tabular}{|c|c|c|c|c|c|}
\hline Factors & $\begin{array}{c}\text { Given } \\
\text { Importance }\end{array}$ & $\begin{array}{c}\text { Desired } \\
\text { Importance }\end{array}$ & $\mathrm{t}$ & $\mathrm{df}$ & $\mathrm{p}$ \\
\hline Tasks \& Processes & 3.58 & 4.21 & -2.532 & 23 & 0.019 \\
\hline Structure & 3.18 & 3.41 & -0.611 & 21 & 0.548 \\
\hline People & 3.33 & 4.79 & -6.061 & 23 & 0.000 \\
\hline Technology & 4.13 & 3.13 & 4.153 & 23 & 0.000 \\
\hline Culture & 2.92 & 4.67 & -7.000 & 23 & 0.000 \\
\hline $\begin{array}{c}\text { Performance/Measuring } \\
\text { Outcomes }\end{array}$ & 3.04 & 3.87 & -2.299 & 22 & 0.031 \\
\hline
\end{tabular}

Table 9 


\begin{tabular}{|c|c|}
\hline Challenges for Research & $\begin{array}{c}\text { Number of } \\
\text { respondents }\end{array}$ \\
\hline $\begin{array}{c}\text { consistent \& cohesive theory supported by } \\
\text { empirical evidence, sound \& stable theoretical } \\
\text { foundation }\end{array}$ & 5 \\
\hline $\begin{array}{c}\text { connecting research and practice } \\
\text { finding/measuring business benefit }\end{array}$ & 2 \\
\hline $\begin{array}{c}\text { industry life } \\
\text { simpler more usable resuls that apply to daily }\end{array}$ & 2 \\
\hline $\begin{array}{c}\text { nind suitable base for research to be cumulative } \\
\text { not ad hoc }\end{array}$ & 1 \\
\hline maintaining a cross disciplinary community & 1 \\
\hline inhibitors and enablers for knowledge use & 1 \\
\hline to shake off technological/elitist aspects & 1 \\
\hline fewer hypotheses, more stimulation of \\
emergence & 1 \\
\hline find potent creation and capture methods & 1 \\
\hline tacit/explicit dimensions, narratives & 1 \\
\hline moving from micro to mezzo level & 1 \\
\hline context & 1 \\
\hline better ways to manage/deal with tacit knowledge & 1 \\
\hline evaluation, sharing processes, organisational \\
impact & 1 \\
\hline be socially effective & 1 \\
\hline funding & 1 \\
\hline integrating people, tech, performance, culture, \\
structure & 1 \\
\hline measuring value added - and not added & 1 \\
\hline & \\
\hline & \\
\hline
\end{tabular}




\begin{tabular}{|l|r|}
\hline Challenges for KM practice & $\begin{array}{l}\text { Number of } \\
\text { respondents }\end{array}$ \\
\hline $\begin{array}{l}\text { measurable successes/metrics \& } \\
\text { measurements, evaluation }\end{array}$ & 4 \\
\hline choosing right KM strategy & 2 \\
\hline how to create trust-based organisational culture & 2 \\
\hline $\begin{array}{l}\text { demonstrate value, motivate people to share } \\
\text { knowledge }\end{array}$ & 1 \\
\hline more attention to explicit knowledge & 1 \\
\hline become integral part of everyday activities & 1 \\
\hline getting the most out of the people & 1 \\
\hline $\begin{array}{l}\text { go beyond large wealthy firms in developed } \\
\text { countries }\end{array}$ & 1 \\
\hline $\begin{array}{l}\text { accepted as fundamental discipline for org } \\
\text { excellence }\end{array}$ & 1 \\
\hline $\begin{array}{l}\text { regaining credibility from vendor/tech dominated } \\
\text { solutions }\end{array}$ & 1 \\
\hline KM impact on organisation's performance & 1 \\
\hline $\begin{array}{l}\text { avoiding disappointment when technologies fail } \\
\text { to deliver }\end{array}$ & 1 \\
\hline $\begin{array}{l}\text { demystify, make part of good org practice \& } \\
\text { strategy dev. }\end{array}$ & 1 \\
\hline $\begin{array}{l}\text { overcoming mgt obsession with financial } \\
\text { issues/Rol }\end{array}$ & 1 \\
\hline $\begin{array}{l}\text { Inter-organisational knowledge transfer and } \\
\text { globalisation }\end{array}$ & 1 \\
\hline to shake off technological/elitist aspects & 1 \\
\hline being part of a process, not being a process & 1 \\
\hline $\begin{array}{l}\text { separate KM from IT and prove its worth } \\
\text { framework that can be applied in any } \\
\text { organisation }\end{array}$ & \\
\hline & 1 \\
\hline
\end{tabular}

